\title{
SENSORES ÓPTICOS COM DETECÇÃO NO INFRAVERMELHO PRÓXIMO E MÉDIO
}

\author{
Kássio M. G. Lima e Ivo M. Raimundo Jr.* \\ Instituto de Química, Universidade Estadual de Campinas, CP 6154, 13084-971 Campinas - SP, Brasil \\ Andréa Monteiro S. Silva \\ Departamento de Química Fundamental, Universidade Federal de Pernambuco, 50670-901 Recife - PE, Brasil \\ Maria Fernanda Pimentel \\ Departamento de Engenharia Química, Universidade Federal de Pernambuco, 50740-521 Recife - PE, Brasil
}

Recebido em 25/10/08; aceito em 5/2/09; publicado na web em 3/7/09

\begin{abstract}
NEAR AND MID INFRARED OPTICAL SENSORS. Optical chemical sensors with detection in the near and mid infrared region are reviewed. Fundamental concepts of infrared spectroscopy and optical chemical sensors are briefly described, before presenting some aspects on optical chemical sensors, such as synthesis of NIR and IR reagents, preparation of new materials as well as application in determinations of species of biological, industrial and environmental importance.
\end{abstract}

Keywords: optical sensors; near infrared; mid infrared.

\section{INTRODUÇÃO}

Nos últimos anos, a busca por métodos analíticos alternativos aos tradicionais tem despertado o interesse de muitos pesquisadores. Em particular, a necessidade de métodos rápidos, versáteis, confiáveis, capazes de monitorar em tempo real espécies de interesse ambiental, industrial e biológico tem incrementado o desenvolvimento e o uso de sensores químicos, tanto eletroquímicos como ópticos, uma vez que agregam vários dos requisitos acima enumerados. Além disso, os sensores químicos são passíveis de miniaturização, permitindo também o monitoramento remoto.

Os primeiros sensores ópticos datam da década de 1930, quando Kautsky e Hirsch propuseram um método para o monitoramento contínuo de oxigênio em baixas concentrações, baseado na supressão de fluorescência da triploflavina e fluoresceina imobilizadas em sílica gel. ${ }^{1}$ Em 1968, Bergman descreveu um sensor óptico para a determinação fluorimétrica de oxigênio baseado na supressão de fluorescência do fluoranteno, um hidrocarboneto policíclico aromático. ${ }^{2} \mathrm{Na}$ década seguinte, em 1975, Lübbers, empregando uma estratégia semelhante à de Bergman, desenvolveu um sensor óptico fluorimétrico para a determinação de oxigênio e dióxido de carbono, empregando, pela primeira vez, um feixe de fibras ópticas. ${ }^{3} \mathrm{O}$ dispositivo proposto foi denominado de optodo (do grego, caminho óptico) ou optrodo (eletrodo óptico), termos igualmente aceitos pela comunidade científica nos dias de hoje. Desde então, os sensores químicos de fibras ópticas têm experimentado um expressivo progresso, sendo encontrados na literatura dispositivos para todo o tipo de analito, desde os mais comuns, como metais pesados, umidade e espécies gasosas, até os emergentes, tais como DNA e bactérias. ${ }^{4}$

Atualmente, a espectroscopia na região do infravermelho tem se destacado como técnica analítica, proporcionando métodos rápidos, robustos, não-destrutivos, não-invasivos, possibilitando aplicações automáticas e em tempo real. Muitos dos métodos baseados na espectroscopia na região do infravermelho médio (MID) ou na região do infravermelho próximo (NIR) empregam um feixe de fibras ópticas para efetuar medidas de reflectância ou transflectância diretamente na amostra, sem a necessidade de pré-tratamento. Esta peculiaridade é facilmente explicada considerando que as fibras ópticas conferem muitas vantagens

*e-mail: ivo@iqm.unicamp.br para medidas em campo e na análise de processos, uma vez que a sonda de fibra óptica "vai" até a amostra, mesmo em locais de difícil acesso, mantendo o instrumento longe de ambientes hostis. Muitos dos métodos analíticos no infravermelho são baseados nas propriedades intrínsecas dos constituintes da amostra e o sinal analítico resulta da interação da radiação eletromagnética com os níveis vibracionais das moléculas. Neste sentido, os métodos no infravermelho baseados em fibras ópticas podem ser classificados no escopo de sensores ópticos, uma vez que a fibra óptica atua passivamente como guia de luz. Este tipo de sensor pertence à primeira geração, possibilitando o sensoriamento remoto desde que uma propriedade óptica intrínseca da amostra possa ser distinguida. Em outras palavras, o analito fornece a informação analítica diretamente, por meio de absorção ou emissão de radiação. ${ }^{5}$

Apesar das considerações feitas acima, na maioria dos casos, o campo de pesquisas referente aos sensores químicos de fibras ópticas implicitamente considera uma fase sensora com um reagente imobilizado, cujas propriedades ópticas se alteram após sua interação com o analito. Esta afirmação não pretende traçar uma rígida linha de divisão entre as áreas de espectroscopia no infravermelho e de sensores ópticos, mas enfatizar a pequena sobreposição destas duas bem estabelecidas linhas de pesquisa.

Considerando estes aspectos, este artigo tem como objetivo apresentar uma visão de sensores ópticos com detecção no infravermelho. Inicialmente, serão apresentados alguns aspectos teóricos sobre espectroscopia no infravermelho e sensores químicos de fibras ópticas, antes de serem discutidos alguns aspectos sobre o desenvolvimento de optodos com detecção no NIR e MID, incluindo aplicações e perspectivas.

\section{ESPECTROSCOPIA NO INFRAVERMELHO ${ }^{6,7}$}

A radiação na região do infravermelho foi descoberta por William Herschel, um astrônomo inglês que, em 1800, estava investigando qual cor da radiação solar produzia calor. ${ }^{8,9}$ Ele empregou um prisma de vidro, transparente à radiação, para decompor a luz branca do sol em seus comprimentos de onda visíveis e, com o auxílio de um termômetro com um bulbo enegrecido, pôde verificar a temperatura produzida por cada cor. Surpreendentemente, a mais intensa variação de temperatura foi observada quando o termômetro foi colocado logo acima da região vermelha do espectro. Herschel chamou esta radiação de "raios caloríficos", que mais tarde foi denominada Infravermelho. 
A espectroscopia no infravermelho trata das variações de energia molecular associadas às transições vibracionais devido à absorção ou emissão de um fóton, que não é suficientemente energético para causar uma transição eletrônica. A energia de um fóton envolvido neste fenômeno é dada por:

$$
E=h \cdot \vee
$$

onde h é a constante de Planck $\left(6,626 \times 10^{-34} \mathrm{~J} \mathrm{~s}\right)$ e $v$ é a frequência de transição. Como a radiação eletromagnética pode ser tratada como uma onda, a energia envolvida neste tipo de transição pode ser também expressa por:

$$
E=h \cdot \mathrm{v}=h \cdot \frac{c}{\lambda}
$$

onde c é a velocidade da luz no vácuo $\left(2,998 \times 10^{8} \mathrm{~m} \mathrm{~s}^{-1}\right)$. A região espectral do infravermelho compreende a radiação com números de onda no intervalo de aproximadamente 12800 a $10 \mathrm{~cm}^{-1}$ ou comprimentos de onda de 780 a $10^{6} \mathrm{~nm}$. Do ponto de vista de aplicação, como também de instrumentação, o espectro no infravermelho é convenientemente dividido em infravermelho próximo (near infrared, NIR, de 780 a $2500 \mathrm{~nm}$ ), médio (mid infrared, MID, de 2500 a 50000 $\mathrm{nm}$ ) e distante (far infrared, FAR, de 50000 a $10^{6} \mathrm{~nm}$ ).

Uma molécula diatômica é a espécie mais simples que pode sofrer uma transição vibracional na região do infravermelho, absorvendo ou emitindo um fóton de energia. Entretanto, o fóton é absorvido (ou emitido) apenas quando ocorre uma variação no momento de dipolo da molécula devido à sua vibração, porque, nesta condição, o campo elétrico da radiação eletromagnética pode interagir com aquele proveniente da vibração da molécula, aumentando a amplitude do movimento vibracional. $\mathrm{Na}$ verdade, a radiação eletromagnética é absorvida quando sua frequência é idêntica à da vibração molecular. O cloreto de hidrogênio $(\mathrm{HCl})$ possui uma distribuição de carga assimétrica, uma vez que o cloro é mais eletronegativo que o hidrogênio. Como consequência, o momento de dipolo da molécula varia durante a vibração, o que resulta em absorção de energia na região do infravermelho. Por outro lado, hidrogênio $\left(\mathrm{H}_{2}\right)$ e cloro $\left(\mathrm{Cl}_{2}\right)$ não absorvem energia nesta região do espectro, uma vez que o momento de dipolo destas moléculas não varia com a vibração. O modelo clássico usado para descrever a vibração de uma molécula consiste de duas massas conectadas por uma mola; uma perturbação na posição de equilíbrio das massas resulta em uma vibração conhecida como movimento harmônico simples. O tratamento mecânico clássico, assim como o mecânico quântico, de um oscilador harmônico não será aqui discutido, uma vez que não é o objetivo principal desta revisão, podendo ser encontrado em detalhes na literatura. ${ }^{6,7}$

Em moléculas, os elétrons sofrem efeitos de átomos ou grupos vizinhos, influenciando o estiramento, o comprimento da ligação, o ângulo de ligação e, portanto, a frequência de vibração das ligações químicas. As diferenças específicas geradas por estas interações possibilitam que cada substância tenha um espectro característico.

A transição vibracional de um estado de energia 0 para 1 ou 2 para 3 ou, em outras palavras, qualquer transição em que a variação dos níveis vibracionais, $\Delta v$, seja \pm 1 é considerada uma transição fundamental. Tais transições são permitidas pela teoria quântica, conforme suas regras de seleção. Essas transições fundamentais são intensas e responsáveis pelas bandas na região do infravermelho médio. A aplicação do MID na identificação de compostos orgânicos é amplamente reconhecida e isso se deve, principalmente, ao fato de nessa região ocorrerem, essencialmente, transições fundamentais e à existência de uma faixa espectral conhecida como região de impressão digital. Nessa região, pequenas alterações na estrutura e na constituição de uma molécula resultam em mudanças significativas na distribuição dos picos de absorção do espectro, que são relacionados com a estrutura da molécula.

Por sua vez, os sinais observados na região do infravermelho próximo ocorrem em frequências aproximadamente duas ou três vezes maiores que as de uma transição fundamental, isto é, $\Delta v= \pm 2$ ou \pm 3 , sendo esse tipo de transição conhecida como sobretom (overtone). A maioria dos sinais do tipo sobretom ocorre na região do NIR, com intensidades cerca de 10 a 1000 vezes menores que as observadas para as transições fundamentais. Este fato é inconsistente com a teoria quântica, uma vez que esta prevê que tais transições seriam proibidas. Outras bandas que aparecem na região do NIR são provenientes das bandas de combinações, que ocorrem quando um fóton excita simultaneamente dois estados vibracionais diferentes. A frequência da banda de combinação é aproximadamente igual à soma ou à diferença entre as duas frequências das bandas fundamentais que interagem para a sua formação.

As bandas de absorção de sobretons ocorrem principalmente entre 12800 e $5500 \mathrm{~cm}^{-1}$ (780 a $\left.1820 \mathrm{~nm}\right)$ e bandas de combinação entre 5500 e $4000 \mathrm{~cm}^{-1}$ (1820 a $\left.2500 \mathrm{~nm}\right)$. Logo, os sinais observados no NIR são essencialmente devidos a esses dois fenômenos, sendo estas absorções correspondentes a sobretons e bandas de combinação de estiramentos e deformações angulares de transições fundamentais de ligações $\mathrm{X}-\mathrm{H}$, onde $\mathrm{X}$ pode ser diferentes elementos químicos ou grupos funcionais, como, por exemplo, oxigênio, nitrogênio, carbono e grupos aromáticos. Outros grupos funcionais importantes incluem estiramentos carbono-oxigênio e grupos carbonila, estiramentos de ligações carbono-nitrogênio, estiramentos de ligações carbono-carbono, dentre outras. Algumas vezes, absorções que ocorrem no NIR são capazes de caracterizar e identificar compostos, como no caso da caracterização de aminas primárias, secundárias e terciárias. Contudo, uma atribuição precisa de bandas na região do NIR é difícil devido ao fato que uma simples banda pode ser atribuída a uma combinação de sobretons e bandas de combinação, todas severamente sobrepostas..$^{10,11}$

De forma geral, as medidas feitas na região do infravermelho NIR ou MID possibilitam o estudo de amostras que podem se encontrar na fase sólida, líquida ou gasosa. Na grande maioria das vezes, não requer grande preparo da amostra e dependendo da técnica utilizada para a análise esta pode ser não destrutiva e relativamente rápida.

\section{SENSORES ÓPTICOS}

Como já mencionado, os sensores químicos de fibras ópticas podem utilizar as propriedades intrínsecas do analito para gerar o sinal analítico em uma medida direta, tais como de índice de refração, absorção ou emissão. Entretanto, mais comumente, as medidas são realizadas indiretamente, isto é, com base na alteração de cor ou luminescência de um indicador ou reagente imobilizado. ${ }^{4}$ Neste sentido, a fase sensora é o elemento primordial de um optodo, pois é constituída pelo reagente imobilizado, devendo possuir características adequadas para uma determinada aplicação. Isto é, o reagente deve estar acessível para interação com o analito, favorecendo uma resposta rápida, sem, entretanto, sofrer lixiviação. Este aspecto é fundamental no desenvolvimento de sensores ópticos, merecendo a atenção contínua de todos os pesquisadores da área, os quais têm proposto diferentes estratégias de imobilização, baseadas em membranas poliméricas, ${ }^{12}$ sol-gel, ${ }^{13}$ polímeros impressos molecularmente, ${ }^{14}$ dentre outras.

Os optodos oferecem vantagens ${ }^{15-17}$ relacionadas às propriedades inerentes destes sensores, como não necessitar de um sinal de referência; não sofrem interferências elétricas ou eletromagnéticas; são seguros para monitoramento in vivo; permitem a transmissão de sinais ópticos a grandes distâncias; detecção em ambientes perigosos, tóxicos, radioativos ou em locais de difícil acesso. São facilmente miniaturizáveis, o que constitui uma vantagem em termos de concepção de dispositivos portáteis para análise in vivo e também quando se dispõe de volume 
reduzido da amostra. Adicionalmente, podem responder a mais de um analito simultaneamente, usando vários reagentes imobilizados, com resposta em diferentes comprimentos de onda. ${ }^{18}$

Os sensores ópticos também apresentam inconvenientes, sofrendo interferência da radiação ambiente, o que obriga, muitas vezes, à modulação do sinal; os reagentes utilizados são suscetíveis a sofrerem fotodecomposição e lixiviação, o que prejudica o tempo de vida do sensor, ${ }^{19}$ o número de reações reversíveis é limitado, necessitando regenerar o sinal de referência a cada medida; apresentam uma faixa de resposta limitada, exceto para a transdução fluorimétrica. Apesar dessas limitações, os sensores ópticos configuram-se como uma alternativa promissora aos procedimentos convencionais e têm sido largamente aplicados em diferentes áreas, como será discutido a seguir.

Com relação à função exercida pela fibra óptica, os sensores podem ser classificados como extrínsecos (Figuras 1a e 1b) ou intrínsecos (Figura 1c). Nos sensores intrínsecos, a fibra óptica é parte fundamental do sistema de medida, afeta diretamente o sinal analítico, devendo estar em contato com a amostra. Na configuração mais usada, uma parte da casca da fibra óptica é substituída por um reagente imobilizado, com índice de refração semelhante, de forma que as propriedades de transmissão da fibra não sejam alteradas significativamente. Quando esta parte da fibra (fase sensora) é colocada em contato direto com a amostra, a interação entre o analito e o reagente pode causar uma variação no índice de refração e/ou no coeficiente de absortividade molar do reagente imobilizado, provocando uma alteração na potência da radiação transmitida devido à interação do campo evanescente..$^{20}$ Nos sensores extrínsecos, a fibra óptica desempenha um papel passivo, apenas conduzindo a radiação da fonte até a fase sensora e desta até o detector. As propriedades ópticas da fase sensora são alteradas com a interação do analito, podendo ser monitoradas por meio de medidas de transmitância, refletância ou fluorescência, nas aplicações mais usuais. Uma abordagem detalhada sobre aspectos fundamentais dos sensores químicos de fibras ópticas pode ser encontrada em livros dedicados a este tema ${ }^{4,21,22}$ e em artigos de revisão, ${ }^{13,23}$ não sendo tratada neste artigo, pois não está diretamente relacionada ao seu principal objetivo.

\section{(A)}
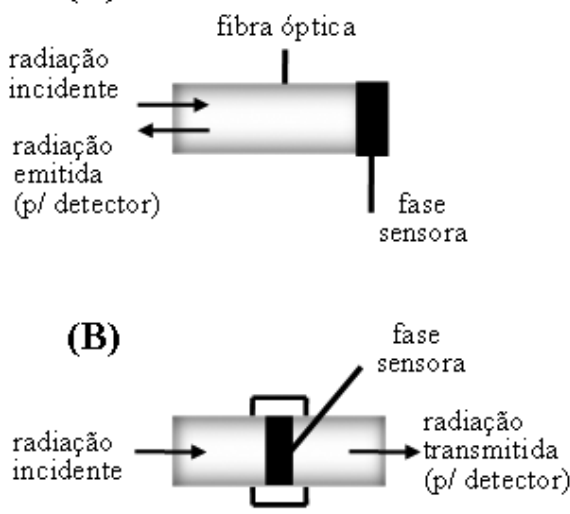

\section{(C)}

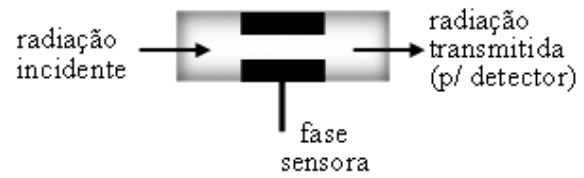

Figura 1. Configurações usuais de sensores químicos de fibras ópticas para medidas de: (a) reflectância; (b) transmitância e (c) ondas evanescentes

\section{SENSORES ÓPTICOS COM DETECÇÃO NO INFRAVERMELHO}

Muitos métodos espectrofotométricos com detecção nas regiões do infravermelho próximo e médio empregam fibras ópticas, sendo baseados nas propriedades intrínsecas do analito. Esta abordagem do problema analítico é muito empregada pelos pesquisadores da área de infravermelho, como pode ser constatado, por exemplo, nos Livros de Resumos da série "International Conference of Near Infrared Spectroscopy". Embora seja considerado um tipo de sensor, algumas vezes chamado de sensor direto, pois não usa um mediador para a transdução do sinal analítico, tem merecido pouca atenção da comunidade de sensores ópticos (como pode ser verificado, por exemplo, nos Livros de Resumo da European Conference on Chemical Sensors and Biosensors), que se dedica mais ao desenvolvimento de fases sensoras com reagente imobilizado. Assim, nesta revisão será dada ênfase aos sensores que empregam uma fase sensora, para a qual o analito presente na solução da amostra é transferido, com a consequente transdução do sinal analítico baseada nas mudanças das propriedades ópticas de um reagente imobilizado, causada pela interação com o analito, ou até mesmo com base nas propriedades do próprio analito.

\section{Reagentes e novos materiais}

O intervalo espectral entre o final da região visível e o início do infravermelho próximo é muito favorável para uso em sensores, pois poucas espécies de ocorrência natural absorvem nessa região, assim como tecidos humanos e fluidos biológicos apresentam uma alta e pouco usual transparência óptica. Além disso, dispositivos de estado sólido compactos e de baixo custo são facilmente encontrados nos dias de hoje. Estes fatos tornam bastante atrativo o desenvolvimento de novos reagentes e novos materiais que absorvam ou sofram fluorescência nesta região. Existem poucos grupos de compostos que apresentam absorção e emissão máxima na região espectral do NIR quando comparado com a região do UV-VIS, pois a absorção e emissão nessa região exigem moléculas com extensas conjugações.

Citterio e colaboradores ${ }^{24-26}$ sintetizaram e caracterizaram cromoionóforos que apresentam absorção na região de 700 a 900 nm. Corantes derivados de esquarina, crocônio e dicianovinila foram imobilizados em membranas de PVC plastificadas, ${ }^{26}$ derivados de cianina, devido à carga positiva, foram imobilizados em Nafion; ${ }^{25}$ enquanto corantes derivados de mero-cianina foram imobilizados em PVC plastificado com DOS (bis(2-etil-hexil)sebacato). ${ }^{24}$ As membranas sensoras demonstraram responder a $\mathrm{pH}$, podendo ser utilizadas para o desenvolvimento de optodos para tal finalidade. Corantes acidocrômicos derivados de 1-benzopirílio, trimetina e hemicianina, que absorvem na região de 600 a $900 \mathrm{~nm}$, foram sintetizados e avaliados para o desenvolvimento de optodos por Czerney e colaboradores. ${ }^{27}$ Estes indicadores, com valores de pKa na faixa de 1 a 8 , mostraram-se estáveis e solúveis em membranas de PVC, podendo ser aplicados para determinação de $\mathrm{pH}$ em reações enzimáticas, assim como para a determinação de prata. Puyol e colaboradores ${ }^{28,29}$ também propuseram cromoionóforos derivados de nortricarbocianinas, com máximos de absorção na faixa de 785 a $830 \mathrm{~nm},{ }^{28}$ assim como derivados de norcianinas, com máximos de absorção entre 648 e $821 \mathrm{~nm},{ }^{29}$ para a determinação de $\mathrm{pH}$. Os pigmentos sintetizados apresentaram alta sensibilidade e diferentes valores de $\mathrm{pKa}$, possibilitando o desenvolvimento de sensores ópticos para uma ampla faixa de $\mathrm{pH}$.

Compostos macrocíclicos polipirrólicos sintéticos, conhecidos como porfirinas expandidas (devido à estrutura análoga, porém de tamanho maior), têm sido propostos por Wong e colaboradores para a determinação de íons prata ${ }^{30}$ e mercúrio. ${ }^{31-33}$ Muito embora a excitação seja na região do visível (absorção em 514 nm), a emissão ocorre com 
grande deslocamento de Stoke, acima de $900 \mathrm{~nm}$, que é suprimida na presença destas espécies metálicas, com grande seletividade. O fluoróforo bis(2-piridil)-boratriazaindacenos foi sintetizado por Coskun e colaboradores, ${ }^{32}$ apresentando uma alta seletividade para íons mercúrio. O reagente livre em solução metanólica, excitado a 660 $\mathrm{nm}$, apresenta um máximo de fluorescência em $682 \mathrm{~nm}$, que decresce com a adição de $\mathrm{Hg}$ (II), produzindo um aumento de fluorescência em $720 \mathrm{~nm}$. Esta propriedade permite que a razão de intensidades de fluorescência nestes dois comprimentos de onda seja empregada como parâmetro analítico, compensando, por exemplo, problemas referentes à lixiviação do reagente imobilizado. Zhu e colaboradore ${ }^{33}$ sintetizaram um cromoionóforo derivado de ditio-dioxo-monoazo-éter-coroa também seletivo a íons mercúrio, o qual causa um deslocamento de $122 \mathrm{~nm}$ no máximo de absorção do indicador (de 695 para $817 \mathrm{~nm}$ ) em medidas efetuadas em solução metanólica. $\mathrm{O}$ reagente pode ser também empregado como um indicador fluorescente, cuja intensidade de fluorescência (em 775 nm, com excitação em $695 \mathrm{~nm}$ ) decresce com a adição da espécie metálica. Uma sonda molecular, obtida pela reação entre um derivado propil-substituído de tricarbocianina com dipicolilamina, foi proposta por Tang e colaboradores ${ }^{34}$ para medidas de $\mathrm{Zn}$ (II) intracelular. Os íons de metais de transição Fe(II), $\mathrm{Fe}$ (III) $\mathrm{Co}$ (II), $\mathrm{Ni}$ (II) e $\mathrm{Hg}$ (II) provocam um pequeno aumento na

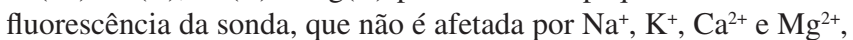
íons que existem em altas concentrações em células. A sonda, na presença de $\mathrm{Zn}$ (II), apresenta uma intensa fluorescência em $780 \mathrm{~nm}$, quando excitada a $731 \mathrm{~nm}$. Basheer e colaboradores ${ }^{35}$ sintetizaram um cromóforo baseado em esquarano seletivo aos íons $\mathrm{Hg}$ (II) e $\mathrm{Pb}$ (II), os quais provocam um deslocamento hipsocrômico de cerca de 220 nm no comprimento de onda de máxima absorção do reagente livre $(770 \mathrm{~nm})$ em medidas realizadas em diclorometano.

Muito embora as contribuições acima citadas não tratem especificamente do desenvolvimento e construção de sensores ópticos, os cromóforos e fluoróforos sintetizados apresentam características de sensibilidade (respondem aos metais em concentrações da ordem de $\mu \mathrm{mol} \mathrm{L} \mathrm{L}^{-1}$ ), seletividade e reversibilidade que os elegem como potenciais reagentes para o desenvolvimento de fases sensoras. Similarmente, Fabian ${ }^{36}$ publicou um artigo de revisão sobre indicadores que absorvem no infravermelho, que pode ser bastante útil para o desenvolvimento de sensores ópticos.

Novos materiais também têm sido empregados no desenvolvimento de membranas sensoras, tais como as baseadas no processo sol-gel. Filmes de sílica porosa, preparados por processo sol-gel, têm sido depositados sobre cristais de ATR (reflectância total atenuada) para o desenvolvimento de sensores ópticos com detecção na região do infravermelho médio. Estes filmes pré-concentram o analito, evitando a interferência da água nas medidas espectroscópicas, como será discutido nos sensores para a determinação de hidrocarbonetos em águas. Lu e colaboradore ${ }^{37}$ avaliaram o desempenho de um filme de sílica mesoporosa hidrofóbica, modificado com grupamento octil, para a determinação de contaminantes orgânicos em água, empregando benzeno como analito teste. $\mathrm{O}$ sensor apresentou uma resposta rápida e reversível ao analito, mas seu desempenho foi demonstrado apenas com uma solução relativamente concentrada do analito (527 $\mathrm{ppm}$ ). Janotta e colaboradore ${ }^{38}$ recobriram um cristal de seleneto de zinco com um filme sol-gel preparado com feniltrimetoxissilano e tetrametoxissilano para determinação dos pesticidas organofosforados paration, fenitrotion e paraoxon. Uma etapa de enriquecimento de 200 min proporcionou um limite de detecção da ordem de subppm, enquanto que em apenas 25 min foi possível a realização de medidas na faixa de ppm. O sensor de ATR recoberto com o sol-gel apresentou uma durabilidade de cerca de 2 meses, com desempenho confiável, o que significa um tempo de vida muito maior que o de um biossensor. Um filme obtido a partir de feniltrimetoxissilano e difenildimetoxissilano (na razão 1:1) foi preparado sobre um cristal trapezoidal de seleneto de zinco e aplicado na determinação de $p$ nitroclorobenzeno por FTIR (espectroscopia na região do infravermelho com transformada de Fourier); um limite de detecção de 0,7 $\mathrm{mg} \mathrm{L}^{-1}$ foi obtido para medidas efetuadas a $35^{\circ} \mathrm{C}$, empregando-se um tempo de pré-concentração de 24 min. ${ }^{39}$

Os nanotubos de carbono também têm sido estudados com vista ao desenvolvimento de sensores ópticos, em virtude de suas propriedades fluorescentes na região do infravermelho próximo. Barone e colaboradores ${ }^{40,41}$ demonstraram que nanotubos de carbono de parede única funcionalizados não-covalentemente com glicose oxidase podem ser empregados no desenvolvimento de sondas para determinação de glicose. Os polímeros impressos molecularmente (MIP, molecularly imprinted polymers) têm sido propostos como elementos de reconhecimento no desenvolvimento de sensores com detecção no infravermelho médio. Jarusch e colaboradores ${ }^{42}$ desenvolveram um sensor de ondas evanescentes para o herbicida 2,4-diclorofenoxiacético, recobrindo um cristal de ATR com um filme de MIP impresso não-covalentemente, com $\sim 5 \mu \mathrm{m}$ de espessura, possibilitando um limite de detecção da ordem de $3 \mu \mathrm{mol} \mathrm{L}^{-1}$, para medidas na faixa de 1306 a $1277 \mathrm{~cm}^{-1}$. Gong e colaboradores ${ }^{43}$ sintetizaram polissiloxanos molecularmente impressos com azo-corantes (disperse red $\mathrm{e}$ disperse blue), avaliando suas especificidades por meio de medidas de reflectância difusa no infravermelho. A seletividade apresentada com relação às moléculas-molde indica a potencialidade destes materiais no desenvolvimento de sensores ópticos.

Um compósito de polianilina-polimetilmetacrilato foi usado no desenvolvimento de um sensor de guia de onda planar baseado em ondas evanescentes para a determinação de amônia. ${ }^{44}$ As medidas foram efetuadas em $980 \mathrm{~nm}$, em uma faixa de concentração de 90 a 4600 ppmv de amônia, indicando uma baixa detectabilidade do sensor

\section{Aplicações}

Diferentes tipos de sensores ópticos podem empregados com o objetivo de se extrair a informação analítica desejada de uma amostra. Como já mencionado neste artigo, os sensores podem ser baseados em medidas de absorbância, reflectância, reflectância total atenuada e fluorescência, dentre outras, técnicas que determinam o arranjo instrumental ao qual deve ser adaptada a fase sensora. Como não é objetivo desta revisão detalhar aspectos técnicos sobre a aquisição dos sinais analíticos, serão discutidas a seguir aplicações em três áreas específicas, nas quais a detecção no infravermelho médio e próximo é frequentemente empregada.

\section{Determinação de espécies de interesse biológico}

Os sensores ópticos têm causado considerável interesse na área biológica. A segurança inerente e as pequenas dimensões do sensor são qualidades desejáveis e, assim, sensores de fibras ópticas têm sido desenvolvidos para fins diversos, com o objetivo de melhorar o limite de detecção, possibilitando também propor métodos de análise a um menor custo. Yang e colaboradores descreveram vários sensores para detecção de compostos de importância biológica, como glicose, ${ }^{45}$ tirosina, ${ }^{46-48}$ arginina, ${ }^{49}$ assim como compostos quirais,${ }^{50}$ empregando um cristal de seleneto de zinco recoberto com diferentes materiais e medidas no infravermelho médio (FTIR). A determinação (indireta) de glicose $\mathrm{e}^{45}$ foi feita recobrindo-se o cristal de ATR com um filme de cloreto de poli(vinilbenzila) contendo $\alpha$-ciclodextrina, previamente modificada com cloreto de tosila e etileno-diamina. A $\alpha$-ciclodextrina aumentou a sensibilidade em cerca de 100 vezes com relação ao cristal convencional, pois forma um complexo de inclusão com o ácido glucônico, produto da reação da glicose com a glicose-oxidase, que foi imobilizada em pérolas de vidro. Com um tempo de reação de $2 \mathrm{~min}$, foi possível 
trabalhar na faixa de concentrações de 1 a $50 \mathrm{mmol} \mathrm{L}^{-1}$, regenerando-se o sensor com soluções aquosas alcalinas. A $\alpha$-ciclodextrina modificada com 1,6-diamino-hexano foi empregada na determinação de tirosina. ${ }^{47}$ O cristal de ATR foi recoberto com uma membrana polimérica de cloreto de poli(vinilbenzila) e poliestireno $(1: 9, \mathrm{~m} / \mathrm{m})$ contendo o reagente modificado. O sensor possui seletividade para a tirosina frente a outros aminoácidos, pois é o único que apresenta uma banda de absorção na região de 1500 a $1270 \mathrm{~cm}^{-1}$. Com um tempo de detecção menor que 5 min, foi possível atingir um limite de detecção de $0,4 \mu \mathrm{mol} \mathrm{L}^{-1}$ e uma faixa linear até $100 \mu \mathrm{mol} \mathrm{L} \mathrm{L}^{-1}$. Mais recentemente, a $\alpha$-ciclodextrina (modificada como descrito na ref. 45) foi usada para recobrir um cristal de seleneto de zinco (como descrito na ref. 47) para a determinação da composição enantiomérica de compostos quirais, ${ }^{50}$ tais como ácido mandélico, ácido acetil-mandélico e ácido canforsulfônico. Um modelo teórico foi desenvolvido e comprovado experimentalmente. Com um sistema em fluxo, o sensor ATR-FTIR pode ser capaz de analisar uma amostra a cada $10 \mathrm{~min}$. Além da $\alpha$-ciclodextrina, duas outras fases sensoras foram empregadas para a determinação de tirosina em fluidos biológicos. Em uma das estratégias, o cristal de ATR foi recoberto com um filme de cloreto de poli(vinilbenzila), posteriormente modificado com L-prolina e saturado com íons cobre. ${ }^{46}$ A detecção de tirosina em solução aquosa foi possível devido à interação deste aminoácido com a fase sensora, formando o complexo prolina-Cu(II)-tirosina, que exibe uma banda de absorção em $1515 \mathrm{~cm}^{-1}$, que confere seletividade ao sensor em relação aos outros aminoácidos que contêm grupos fenila, possibilitando um limite de detecção de $3 \mu \mathrm{mol} \mathrm{L}{ }^{-1}$. Na outra estratégia, vários ácidos aminocarboxílicos (derivados de tris(2-aminoetil)amina, n-butilamina, p-fenilenodiamina, anilina e 1,2-diaminoetano) foram empregados para modificar um filme de cloreto de poli(vinilbenzila) e poliestireno $(3: 2, \mathrm{~m} / \mathrm{m})$, previamente imobilizado sobre o cristal de ATR.$^{48} \mathrm{O}$ derivado ácido da tris(2-aminoetil)amina apresentou o melhor desempenho para a determinação de tirosina em urina, empregandose uma estratégia similar ao sensor acima descrito, com a saturação da fase sensora com íons Ni(II). As interferências dos aminoácidos fenólicos foram também observadas, mas a seletividade foi conseguida realizando-se as medidas em $1515 \mathrm{~cm}^{-1}$. A faixa de resposta foi linear até $600 \mu \mathrm{mol} \mathrm{L}{ }^{-1}$, com um limite de detecção de $30 \mu \mathrm{mol} \mathrm{L}^{-1}$. Para a determinação de arginina em fluidos biológicos, o filme de cloreto de poli(vinilbenzila) e polietileno usado para recobrir o cristal foi modificado com grupos sulfonatos, que interagem seletivamente com este aminoácido.$^{49} \mathrm{O}$ sensor também respondeu à lisina, histidina e arginina em pH 9, cujas interferências foram evitadas realizando-se medidas em $1665 \mathrm{~cm}^{-1}$. Nas condições otimizadas, um limite de detecção de 5 $\mu \mathrm{mol} \mathrm{L} \mathrm{L}^{-1}$ foi obtido, com uma faixa de resposta linear até $0,1 \mathrm{mmol} \mathrm{\textrm {L } ^ { - 1 }}$.

Um sensor de fibra de vidro de calcogeneto, $\left(\mathrm{Te}_{2} \mathrm{As}_{3} \mathrm{Se}_{5}\right)$, baseado em medidas de ondas evanescentes na região do infravermelho médio ( $800 \mathrm{a} 4000 \mathrm{~cm}^{-1}$ ) foi desenvolvido por Keirsse e colaboradores. ${ }^{51}$ Para aumentar a sensibilidade do sensor, o diâmetro da fibra foi diminuído na região de medida. O sistema sensor foi aplicado no estudo de transformações metabólicas em tecidos biológicos complexos (fígado de rato), assim como no monitoramento da evolução de células vivas durante o processo de diferenciação. Muito embora não empregue um reagente imobilizado, este sistema demonstra as potencialidades dos sensores de fibras ópticas no estudo de processos biológicos. Para finalizar, deve ser mencionado o trabalho de Barone e colaboradores ${ }^{40,41}$ visando o desenvolvimento de sensores de nanotubos de carbono para a determinação de glicose, como discutido acima.

\section{Determinação de espécies de interesse industrial}

Os sensores químicos de fibras ópticas com detecção na região do infravermelho têm grande potencial para o monitoramento em tempo real de processos industriais, dada a habilidade para medidas remotas e em condições hostis. Acha e colaboradores ${ }^{52}$ recobriram um cristal de ATR de seleneto de zinco com poliisobutileno e polietileno de baixa densidade no desenvolvimento de um sensor para monitoramento contínuo de tricloroetileno, tetracloroetileno e tetracloreto de carbono em um biorreator de leito fixo empregado em um processo de descloração. A etapa de extração/concentração dos hidrocarbonetos clorados no filme polimérico eliminou a interferência da água, possibilitando a obtenção de limites de detecção de 2,0; 3,0 e 2,5 mg L-1 para os três hidrocarbonetos clorados, respectivamente. Lucena e colaboradores $^{53}$ descreveram um método utilizando um sensor baseado em medidas de ATR/MID para a determinação simultânea de índices de surfactante e de óleo total em banhos desengordurantes industriais. Nesse trabalho, a superfície do elemento de reflexão interna não foi recoberta com uma membrana polimérica, mas uma membrana de PTFE foi colocada em uma câmara externa, permitindo a difusão do analito da fase aquosa para a fase orgânica, seguindo uma extração líquido-líquido. Após esta etapa, o analito foi quantificado na superfície do cristal de ATR, empregando-se um sistema de análise por injeção sequencial automático conectado on-line ao espectrômetro. Os autores construíram modelos PLS (mínimo quadrados parciais) para esses dois analitos e compararam os erros de previsão com relação ao método gravimétrico de referência. Os baixos erros de previsão obtidos mostraram a potencialidade do método para essa aplicação. Bentrup e colaboradores ${ }^{54}$ investigaram o uso de um sensor óptico baseado em fibra de haleto de prata acoplada a um prisma de diamante para acompanhar várias etapas no processo de síntese de análogos de vitamina D. Os ensaios semiquantitativos indicaram que o sistema proposto pode ser aplicado no controle dos processos, por meio de medidas na região de 4000 a $650 \mathrm{~cm}^{-1}$. A aplicação e as potencialidades da espectroscopia no infravermelho médio no monitoramento de bioprocessos em tempo real foram discutidas recentemente por Roychoudhury e colaboradore ${ }^{55} \mathrm{em}$ um artigo de revisão, que concluíram que a técnica está suficientemente amadurecida para monitorar bioprocessos complexos. Uma revisão mais geral foi apresentada por Vojinovic e colaboradores, ${ }^{56}$ apresentando as vantagens e limitações tanto da espectroscopia NIR como da MID. Em ambas as referências são descritas contribuições, que podem ser consultadas pelo leitor interessado na referida área.

Um sensor óptico distribuído, que permite medidas simultâneas em diferentes pontos, foi proposto por Buerck e colaboradores ${ }^{57}$ para o monitoramento de vazamentos de hidrocarbonetos em tanques e tubulações. Os autores empregaram uma fibra de sílica recoberta com silicone, efetuando medidas em $850 \mathrm{~nm}$ por meio de reflectância óptica resolvida no tempo (OTDR, optical time domain reflectance). Uma fibra de $1 \mathrm{~km}$ foi empregada para demonstrar a potencialidade do sensor, medindo-se a variação da intensidade da radiação que atinge o detector, causada pela mudança do índice de refração da casca de silicone em função da quantidade de hidrocarboneto extraído. Vários hidrocarbonetos foram avaliados (clorados, oxigenados, aromáticos), demonstrando a viabilidade do sensor para esta aplicação.

\section{Determinação de espécies de interesse ambiental}

As aplicações mais usuais referem-se à contaminação de águas por hidrocarbonetos. Em geral, não é possível a determinação direta de hidrocarbonetos aromáticos e/ou clorados em águas empregando espectroscopia no infravermelho, em virtude da baixa concentração dessas espécies em água, a qual, por sua vez, também apresenta uma alta absorção nessa região do espectro eletromagnético. Os sensores ópticos, tanto com detecção no NIR como no MID, têm sido frequentemente empregados na determinação destes hidrocarbonetos, valendo-se de uma fase polimérica que extrai o analito da fase aquosa, eliminando a interferência, além de proporcionar a sua pré-concentração. O principal desafio nesta área de aplicação de sensores ópticos é o desenvolvimento de métodos simples e robustos, 
com sensibilidade e detectabilidade similares à da cromatografia gasosa, técnica usualmente empregada para a determinação destas espécies em águas.

As medidas espectrofotométricas, em ambos os tipos de detecção, são geralmente realizadas com base no princípio de ondas evanescentes. Para tanto, nos sistemas com detecção no infravermelho médio (geralmente FTIR), um cristal de seleneto de zinco é recoberto com um filme polimérico apropriado, para extração e pré-concentração do hidrocarboneto de interesse, como descrito anteriormente. $\mathrm{O}$ sinal é obtido por medida de reflectância total atenuada, em um procedimento similar ao convencional. A principal desvantagem desta estratégia refere-se ao cuidado necessário para recobrir o cristal de ATR, assim como para retirar o filme polimérico. No infravermelho próximo, é normalmente empregada uma fibra óptica de núcleo de sílica recoberto com uma casca polimérica, que é conectada da fonte de radiação diretamente ao detector, em um esquema similar ao mostrado na Figura 1c. O sinal analítico origina-se como consequência da transferência do hidrocarboneto da fase aquosa para a casca polimérica, que altera a potência da radiação transmitida devido tanto à absorção de luz como à mudança do índice de refração. Esta configuração é também empregada em medidas no MID. Embora a espectroscopia NIR faça uso de uma instrumentação mais robusta que a da espectroscopia MID, o esquema de medida possui como desvantagem a necessidade de fibras ópticas longas, que são bastante frágeis e fáceis de serem danificadas.

\section{Detecção no MID}

Diferentes tipos de membranas poliméricas têm sido investigados, considerando a influência das propriedades dos polímeros, como temperatura de transição vítrea, cristalinidade, coeficiente de partição, absorção na região do infravermelho, assim como a espessura da membrana polimérica no desempenho do sensor. Gobel e colaboradores ${ }^{58}$ estudaram a difusão de três hidrocarbonetos clorados (monoclorobenzeno, clorofórmio e tetracloroetileno) em oito diferentes polímeros (polietileno de baixa densidade, copolímero etileno-propileno, 1,2-polibutadieno, poli-isobutileno, polietileno oxidado, polietileno clorado, copolímero etileno-vinilacetato e poli(4-metil-1-penteno), utilizando medidas de reflexão total atenuada (ATR) com um cristal de ZnSe recoberto pelo polímero $(22 \pm 2$ $\mu \mathrm{m})$. Os resultados indicaram que para se obter $90 \%$ de saturação da fase sensora era necessário um tempo de 8 a 40 min, dependendo da natureza do polímero. Com 5 min de extração, empregando-se um filme de poli-isobutileno, um limite de detecção na faixa de 1,5 a 2 $\mathrm{mg} \mathrm{L}^{-1}$ foi obtido para os três analitos. Em um trabalho subsequente, Gobel e colaboradores ${ }^{59}$ investigaram a difusão dos mesmos hidrocarbonetos clorados em algumas membranas poliméricas (polietileno de baixa densidade, copolímero etileno-propileno e poli-isobutileno) por meio de modelos teóricos. Os resultados obtidos demonstraram a importância do entendimento do processo de difusão em diferentes materiais poliméricos para otimizar o sistema sensor de fibra óptica para a determinação de hidrocarbonetos clorados em águas.

Flavin e colaboradores ${ }^{60}$ avaliaram os polímeros Teflon AF2400, poli(acrilonitrila-co-butadieno), polidimetilsiloxano (PDMS) e poli(estireno-co-butadieno) como membranas para pré-concentração na determinação de tolueno, tetra-hidrofurano, etanol e acetonitrila, investigando parâmetros como coeficiente de difusão, valores de absorbância no equilíbrio, dentre outros. Concluíram que a escolha do meio pré-concentrador não é uma tarefa trivial, indicando que o poli(acrilonitrila-co-butadieno) apresenta a resposta mais rápida, com maior sensibilidade. Em um trabalho posterior, Flavin e colaboradores ${ }^{61}$ estudaram o efeito de vários solventes orgânicos (tolueno, etilbenzeno, xilenos, clorobenzeno, tetra-hidrofurano, dentre outros) no deslocamento das bandas de absorção do Teflon AF2400 suportado sobre um cristal de ATR, correlacionando este efeito com o índice de refração do analito e sua difusão no polímero, com o objetivo de desenvolver um sensor inteligente para resíduos de solventes. O Teflon AF2400 também foi empregado por Murphy e colaboradores ${ }^{62,63} \mathrm{em}$ estudos semelhantes ao de Flavin, ${ }^{60,61}$ sendo concluído que tamanho, forma, solubilidade na água e no polímero, além de efeitos multicomponentes, afetam a difusão do analito (dicloroetileno, tricloroetileno, tetracloroetileno, cloropentano, clorciclopentano, diclorobenzeno, triclorobenzeno, dentre outros) no polímero e devem ser considerados no desenvolvimento e otimização de uma unidade sensora.

Regan e colaboradores ${ }^{64}$ também empregaram um cristal de ATR recoberto com um filme de PVC plastificado para a determinação de benzeno, tolueno, etilbenzeno e xilenos (BTEX) em águas. Dez plastificantes foram estudados, sendo empregados tolueno e tetracloroetileno como analitos teste. A membrana preparada com PVC e diiso-octil-azelato mostrou ser a mais promissora para a determinação de BTEX em águas, possibilitando determinações em menos de 8 min. Pesquisadores do mesmo grupo descreveram sensores ópticos baseados em fibras ópticas de haleto de prata recobertas com material polimérico para a determinação de hidrocarbonetos. ${ }^{65-67}$ Fibras recobertas com PVC e poli-isobutileno mostraram-se adequadas para a determinação de pesticidas e hidrocarbonetos clorados, respectivamente, proporcionando limites de detecção na faixa de $\mathrm{mg} \mathrm{L}^{-1}{ }^{65}$ Teflon como material de recobrimento foi empregado para a determinação de tricloroetileno em águas, sendo que o sensor apresentou um tempo de resposta de $3 \mathrm{~min}$, uma faixa de resposta linear de 5 a $50 \mathrm{mg}$ $\mathrm{L}^{-1}$ e um limite de detecção de $1,0 \mathrm{mg} \mathrm{L}^{-1}{ }^{66} \mathrm{Um}$ sistema modular, que emprega uma fibra óptica de halogeneto de prata recoberta com PVC, foi avaliado, fornecendo um limite de detecção de $500 \mathrm{mg} \mathrm{L}^{-1}$ para o benzeno. ${ }^{67}$

Kraft e colaboradores ${ }^{68}$ desenvolveram um submarino sensor com detecção FTIR para determinação de compostos orgânicos voláteis em profundidades de $300 \mathrm{~m}$. Uma fibra de halogeneto de prata recoberta com um filme de copolímero etileno-propileno foi empregada na transdução química do sinal, permitindo a determinação de compostos aromáticos clorados (clorobenzeno, 1,2-diclorobenzeno, triclorobenzeno e tetraclorobenzeno) em concentrações tão baixas quanto $100 \mu \mathrm{g} \mathrm{L} \mathrm{L}^{-1}$

O processo sol-gel também tem sido empregado por Janotta e colaboradores na modificação de cristal de seleneto de zinco com feniltrimetoxissilano e tetrametoxissilano para a determinação de pesticidas em águas por FTIR, como descrito anteriormente. ${ }^{38}$ Estes mesmos silanos têm sido usados como precursores no recobrimento de fibras de halogeneto de prata para o desenvolvimento de sensores para a determinação de nitrobenzeno e paration, conseguindo-se atingir limites de detecção da ordem de $\mathrm{mg} \mathrm{L}^{-1}{ }^{-69}$

Métodos baseados em medidas de transmitância também têm sido descritos, empregando membranas sensoras poliméricas em uma etapa prévia de extração e pré-concentração do analito. ${ }^{70-72}$ Tilotta e colaboradores avaliaram o Parafilm M (espessura de $130 \mu \mathrm{m}$ ) como fase sensora na determinação de compostos orgânicos voláteis (benzeno, clorobenzeno, tolueno, clorofórmio, dentre outros), obtendo limites de detecção na faixa de $66 \mu \mathrm{g} \mathrm{L}^{-1}$ a 1,3 $\mathrm{mg} \mathrm{L}^{-1}$, com tempos de extração na faixa de 30 a 200 min, muito embora extrações reprodutíveis tenham sido efetuadas em apenas $30 \mathrm{~min}$. Em trabalho similar, ${ }^{71}$ uma membrana de PDMS foi empregada na determinação de tricloroetileno, percloroetileno, trifularin e $o$ - e $p$-xileno, proporcionando um tempo de 60-85 min para se atingir o equilíbrio na extração, com um limite de detecção de 0,2 a 4,4 $\mathrm{mg} \mathrm{L}^{-1}$, dependendo do analito. Embora tenha apresentado, de maneira geral, um desempenho inferior ao do Parafilm, o PDMS possibilitou um menor limite de detecção para trifluralin $\left(190 \mu \mathrm{g} \mathrm{L}^{-1}\right)$. Adotando a mesma estratégia de membrana polimérica para extração do analito, recentemente Silva e colabora- 
dores $^{72}$ investigaram o uso de filmes de PVC, preparado com Tinuvin (2-(2-hidroxi-5-tert-octifenil) benzotriazol) como estabilizante e DOP (di-2-etil-hexil ftalato) como plastificante como fase sensora na determinação de BTEX em águas contaminadas. As medidas de transmitância foram realizadas diretamente na fase sensora de PVC $\left(54 \mathrm{~mm}^{2}\right)$ na região do MID. O estudo cinético mostrou que os filmes de PVC alcançam a saturação num tempo inferior a $180 \mathrm{~min}$ para todos os analitos, apresentando limites de detecção abaixo de $10 \mathrm{mg}$ $\mathrm{L}^{-1}$ para todos os analitos estudados.

\section{Detecção no NIR}

Neste caso, a maioria das aplicações emprega sensores ópticos intrínsecos, que se valem das propriedades das fibras ópticas revestidas com determinados polímeros, possibilitando interações com o analito. A aplicabilidade destes sensores de fibras ópticas com núcleo de sílica e casca de polímero tem sido demonstrada com medidas em hidrocarbonetos puros. ${ }^{73,74}$ Degrandpre e Burgess ${ }^{73}$ realizaram medidas na região de 1000 a $2200 \mathrm{~nm}$ com hexano, clorofórmio, tetracloreto de carbono e as misturas binárias de clorofórmio/tetracloreto e tolueno/ciclo-hexano. Uma fibra óptica de $3 \mathrm{~m}$, com núcleo de $400 \mu \mathrm{m}$ de diâmetro e revestimento polimérico de polissiloxano de $500 \mu \mathrm{m}$ foi utilizada no registro de espectros NIR para investigar equilíbrios de fase solvente/polímero. Tobiska e colaboradores ${ }^{74}$ investigaram, na região de 900 a $1700 \mathrm{~nm}$, o comportamento de n-heptano, tolueno e gasolina em medidas com fibras ópticas de 0,2 e $8 \mathrm{~m}$ de comprimento e núcleos de sílica de 0,2 a 0,38 $\mathrm{mm}$ com recobrimento de PDMS com espessuras entre 15 e $20 \mu \mathrm{m}$. Após uma etapa de secagem da fibra a $70^{\circ} \mathrm{C}$ por $24 \mathrm{~h}$, foram investigados parâmetros de reversibilidade e tempo de resposta para os compostos estudados. O sensor mostrou ser reversível para todos os compostos, com tempos de respostas entre 19 e $60 \mathrm{~min}$.

Um sensor intrínseco foi desenvolvido por Bürck e colaboradores $^{75}$ para a determinação de diclorometano, clorofórmio e tricloroetileno em águas, com medidas na região espectral de 900 a 2100 nm, empregando-se uma fibra óptica de $8 \mathrm{~m}$, com núcleo de sílica de 400 $\mu \mathrm{m}$ de diâmetro e casca de polissiloxano de $500 \mu \mathrm{m}$. A fibra foi adaptada na forma de espiral dentro de um suporte de teflon, sendo colocada em contato com soluções dos hidrocarbonetos clorados, realizandose medidas com base no princípio de ondas evanescentes. A jaqueta protetora de nylon da fibra óptica foi removida com 1,2-propanodiol a $160^{\circ} \mathrm{C}$. Os tempos de resposta para o diclorometano, clorofórmio e tricloroetileno variaram de 5 a $10 \mathrm{~min}$, com respostas lineares na faixa de concentração entre $80-6800 \mathrm{mg} \mathrm{L}^{-1}$, que são relativamente altas. Estes autores empregaram um sistema similar para estudar a cinética de transferência destes hidrocarbonetos clorados da solução aquosa para o filme de polissiloxano, concluindo que a etapa determinante para a penetração destas substâncias no polímero pode ser descrita principalmente pela difusão através da camada aquosa limite. ${ }^{76} \mathrm{~A}$ determinação simultânea destes hidrocarbonetos clorados foi também proposta pelos mesmos autores, empregando a regressão por mínimos quadrados parciais. Resultados satisfatórios puderam ser obtidos com erros quadráticos de previsão da ordem de $0,3 \mathrm{mg} \mathrm{L}^{-1}$ para misturas de dicloroetileno e tricloroetileno na faixa de concentração de 1-9 $\mathrm{mg} \mathrm{L}{ }^{-1} .^{77} \mathrm{O}$ mesmo conceito de sensor foi empregado por Bürck e colaboradores ${ }^{78} \mathrm{em} 1994$, para a determinação de diclorometano, tricloroeteno, 1,2,3-triclorobenzeno, tolueno e p-xileno in situ em águas. Para isso, utilizaram uma fibra óptica de $10,58 \mathrm{~m}$, também disposta em espiral dentro de um suporte de Teflon de geometria cilíndrica, com núcleo de sílica de $400 \mu \mathrm{m}$ de diâmetro e revestimento polimérico de PDMS com $100 \mu \mathrm{m}$ de espessura. Várias curvas analíticas foram construídas para cada espécie química, sendo verificada uma distinção entre os coeficientes angulares, mostrando que a sensibilidade para cada um dos compostos depende de seu coeficiente de distribuição no sistema água/silicone. O tempo de resposta e o limite de detecção variaram, respectivamente, de 0,5 a 71 min e de 0,1 a $80 \mathrm{mg} \mathrm{L}^{-1}$ para os clorados e de 16 a 32 min e 0,4 e $0,9 \mathrm{mg} \mathrm{L}^{-1}$ para os aromáticos. Em 2001, Buerck e colaboradores ${ }^{79}$ aplicaram um sensor NIR-EFA (near-infrared-evanescent field absorption) no monitoramento in situ de hidrocarbonetos aromáticos (BTEX) em águas residuárias. Foi empregada uma fibra óptica com comprimento de 12-30 m, $210 \mu \mathrm{m}$ de diâmetro, $10 \mu \mathrm{m}$ de revestimento polimérico de PDMS. Na faixa de concentração de 0,2 a $150 \mathrm{mg} \mathrm{L}^{-1}$, foi obtida uma linearidade superior a 0,995 para os compostos estudados, com um limite de detecção de $0,2 \mathrm{mg} \mathrm{L}^{-1}$ e tempo de resposta entre 2 e 5 min.

Um sensor óptico integrado, baseado em medidas de absorbância por ondas evanescentes com FT-NIR, foi proposto por Mayer e colaboradores. ${ }^{80}$ Os autores avaliaram parâmetros como tipo de revestimento polimérico da fibra óptica (PDMS, mercaptopropil/PDMS ou resina de silicone acrilada) espessura do filme polimérico e índice de refração, obtendo para o tricloroetileno um limite de detecção de $22 \mathrm{mg} \mathrm{L}^{-1}$, com tempo de resposta entre 5 e 40 min para uma espessura de filme de aproximadamente de $30 \mu \mathrm{m}$. A resposta do sensor foi totalmente reversível após a exposição da fibra óptica ao ar por 2 min.

As propriedades de membranas constituídas por siloxanos para o monitoramento de compostos orgânicos apolares em águas foram

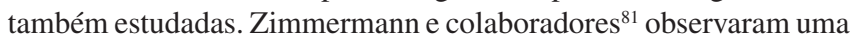
melhora na extração desses compostos quando foram inseridos radicais fenil/metil à membrana de PDMS. $\mathrm{O}$ coeficiente de partição do tricloroetileno, composto modelo empregado no estudo dos diferentes sistemas água/polímero, aumentou em um fator de 1,7 quando foi empregado fenilmetilsiloxano na razão molar 1:1 em vez de polidimetilsiloxano, melhorando, como consequência, as sensibilidades das curvas analíticas.

Chomat e colaboradores ${ }^{82}$ propuseram a detecção de tolueno em águas empregando uma fibra de $4 \mathrm{~cm}$ de comprimento, com um filme de dimetilpolissiloxano $(80 \mu \mathrm{m})$ depositado por dip-coating. Dois tipos de exposições foram estudados, um no qual o sensor foi mantido sob exposição estática à solução do hidrocarboneto e o outro sob um fluxo constante da solução aquosa. Em apenas 5 min sob condições estáticas atingiu-se um limite de detecção de $4,4 \mathrm{mg} \mathrm{L}^{-1}$, enquanto 2,5 min de exposição dinâmica foram necessários para se obter um limite de detecção de $2,8 \mathrm{mg} \mathrm{L}^{-1}$.

Outros tipos de material, diferentes dos polissiloxanos, têm também sido propostos como recobrimento do núcleo das fibras ópticas para o desenvolvimento de sensores. Como exemplo pode ser citado o xerogel preparado a partir de tetraetoxissilano, metiltrietoxissilano e uma mistura de metiltrietoxissilano e feniltrietoxissilano avaliado por Skokankova e colaboradores, ${ }^{83}$ empregando a determinação de tolueno em água. Os resultados experimentais mostraram que a fibra recoberta pelo xerogel baseado em metiltrietoxissilano apresentou maior sensibilidade para o tolueno, com limite de detecção de $5 \mathrm{mg} \mathrm{L}^{-1}$.

Blair e colaboradores ${ }^{84}$ propuseram um modelo baseado na lei de difusão de Fick para o transporte de massa de hidrocarbonetos clorados do meio aquoso para o meio polimérico. Coeficientes de difusão de $3 \times 10^{-7}, 5 \times 10^{-7}$ e $1 \times 10^{-7} \mathrm{~cm}^{2} \mathrm{~s}^{-1}$ foram obtidos para tricloroetileno, 1,1,1-tricloroetano e tolueno, respectivamente. Os autores também realizaram um estudo de calibração multivariada empregando regressão por componentes principais (PCR) e regressão por mínimos quadrados parciais (PLS). Os valores de RMSEP (raiz quadrada dos erros médios quadráticos de previsão) resultantes para $\mathrm{o}$ modelo PCR foram de 29,23 e $32 \mathrm{mg} \mathrm{L}^{-1}$, enquanto que para o modelo PLS foram de 29, 20 e $32 \mathrm{mg} \mathrm{L}^{-1}$ para tricloroetileno, tricloroetano e tolueno, respectivamente.

O efeito da variação de temperatura na transmissão do sinal em fibras ópticas revestidas por filmes poliméricos foi investigado em bandas de absorção de gasolinas no NIR por Santoyo e colabora- 
dores. ${ }^{85}$ Mudanças termoinduzidas em medidas de transmitância das fibras ópticas tiveram fortes efeitos em função do comprimento de onda utilizado. Os autores concluíram que a região ao redor de 1214 nm está livre de efeitos térmicos, observando-se sensibilidade suficiente para detecção de gasolinas comerciais.

Como afirmado anteriormente, a principal desvantagem dos sensores ópticos baseados em ondas evanescentes é a necessidade de se empregar fibras ópticas relativamente longas, de forma a se obter a detectabilidade apropriada. Para contornar esta desvantagem, Albuquerque e colaboradore ${ }^{86}$ propuseram o uso de uma fase sensora de silicone (PDMS) para a detecção de compostos BTEX. As medidas foram realizadas com uma sonda de transflectância, usando-se fases sensoras com alturas de 1,0; 5,0 e 10,0 mm (que determinam o caminho óptico) e diferentes diâmetros (3,2; 5,0 e 7,0 mm). A fase sensora com 3,2 mm de diâmetro e $10,0 \mathrm{~mm}$ de altura apresentou respostas reversíveis e limites de detecção de 8,0; 7,0; 2,6 e 3,0 mg $\mathrm{L}^{-1}$ de benzeno, tolueno, etilbenzeno e m-xileno, respectivamente. Dando continuidade a este trabalho, Lima e colaboradores ${ }^{87}$ demonstraram que o emprego de cloreto de sódio na etapa de extração dos hidrocarbonetos da solução aquosa maximiza a pré-concentração no polímero através do efeito salting out. Para fases sensoras de $5 \mathrm{~mm}$ de comprimento, usando-se $\mathrm{NaCl} 2 \mathrm{~mol} \mathrm{~L}^{-1}$, foram obtidos limites de detecção de 0,$08 ; 0,12 ; 0,14$ e $0,27 \mathrm{mg} \mathrm{L}^{-1}$ para benzeno, tolueno, etilbenzeno e xilenos, respectivamente. Estes resultados são bastante promissores no sentido de se obter um método analítico com detecção no infravermelho próximo, simples e de baixo custo, que venha a substituir os métodos usuais baseados em cromatografia gasosa.

\section{CONCLUSÕES E PERSPECTIVAS}

Os sensores ópticos com detecção no infravermelho próximo e médio têm um espaço fundamental no desenvolvimento de métodos analíticos simples, robustos e de baixo custo. Os avanços recentes na área de miniaturização e no desenvolvimento de fibras ópticas de qualidade transparentes na região do infravermelho deverão possibilitar uma efetiva contribuição deste tipo de sensor, tanto no monitoramento ambiental remoto e contínuo, como no monitoramento in vivo. A síntese de reagentes e a produção de novos (nano)materiais com propriedades ópticas apropriadas na região do infravermelho deverão direcionar o desenvolvimento de novos dispositivos, capazes de responder às mais diversas demandas analíticas, como, por exemplo, as mencionadas neste artigo.

\section{AGRADECIMENTOS}

Ao CNPq e à CAPES pelos auxílios financeiros e bolsas concedidos. Ao Programa Nacional de Cooperação Acadêmica (PROCAD/ CAPES 0081/05-1), que possibilitou uma efetiva colaboração entre os grupos de pesquisa da UFPE e da Unicamp, cujos resultados também estão descritos neste artigo.

\section{REFERÊNCIAS}

1. Kautsky, H.; Hirsch, A.; Berichte der Deutschen Chemischen Gesellschaft 1931, 64, 2677.

2. Bergman, I.; Nature 1968, 218, 266.

3. Lübbers, D. W.; Opitz, N.; Z. Naturforsch. 1975, 30c, 532.

4. Wolfbeis, O. S.; Anal. Chem. 2008, 80, 4269.

5. Wolfbeis, O. S.; Fiber Optic Chemical Sensors and Biosensors, CRC Press: Boca Raton, 1991, vol. I e II.

6. Pasquini, C.; J. Braz. Chem. Soc. 2003, 14, 198.

7. Skoog, D. A.; Holler, F. J.; Crouch, S. R.; Principles of Instrumental Analysis, 6 $^{\text {th }}$ ed., Thomson Brooks: USA, 2007.
8. Herschel, W.; Phil Trans. Roy. Soc. London 1800, Part II, 255.

9. Herschel, W.; Phil Trans. Roy. Soc. London 1800, Part II, 284.

10. Jerome, J.; Workman, J. R.; Appl. Spectrosc. Rev. 1996, 31, 251.

11. Bums, D. A.; Ciurczak, E. W.; Handbook of Near-Infrared Analysis, $2^{\text {nd }}$ ed., Marcel Dekker: New York, 2001.

12. Khezri, B.; Amini, M. K.; Firooz, A. R.; Anal. Bioanal. Chem. 2008 , 390, 1943.

13. Jeronimo, P. C. A.; Araujo, A. N.; Montenegro, M. C. B. S. M.; Talanta 2007, 72, 13 .

14. Ng, S. M.; Narayanaswamy, R.; Anal. Bioanal. Chem. 2006, 386, 1235.

15. Newcombe, D. T.; Cardwell, T. J.; Cattrall, R. W.; Kolev, S. D.; Anal. Chim. Acta 1999, 395, 27.

16. Norris, J.; Analyst 1989, 114, 1359.

17. Gupta, V. K.; Chandra, S.; Mangla, R.; Eletrochim. Acta 2002, 47, 1579.

18. Skibsted, E.; Lindemann, C.; Roca, C.; Olsson, L.; J. Biotechnol. 2001, $88,47$.

19. Taib, M. N.; Narayanaswamy, R.; Analyst 1995, 120, 1617.

20. Cao, W.; Duan, Y.; Sens. Actuators, B 2006, 119, 363.

21. Janata, J.; Principles of Chemical Sensors, Plenum Press: New York, 1990.

22. Spichiger-Keller, U. E.; Chemical Sensors and Biosensors for Medical and Biological Applications, Wiley-VCH: Weinheim, 1998.

23. McDonagh, C.; Burke, C. S.; MacCraith, B. D.; Chem. Rev. 2008, 108, 400.

24. Citterio, D.; Kawada, T.; Yagi, J.; Ishigaki, T.; Hisamoto, H.; Sasaki, S-I.; Suzuki, K.; Anal. Chim. Acta 2003, 482, 19.

25. Citterio, D.; Rásonyi, S.; Spichiger, U. E.; Fresenius' J. Anal. Chem. 1996, 354, 836

26. Citterio, D.; Jenny, L.; Rásonyi, S.; Spichiger, U. E.; Sens. Actuators, B 1997, 38-39, 202

27. Czerney, P.; Grummt, U-W.; Sens. Actuators, B 1997, 38-39, 395

28. Puyol, M.; Encinas, C.; Rivera, L.; Miltsov, S.; Alonso, J.; Sens. Actuators, $B$ 2007, 122, 53.

29. Puyol, M.; Encinas, C.; Rivera, L.; Miltsov, S.; Alonso, J.; Dyes Pigm. 2007, 73, 383.

30. Zhu, X.; Fu, S.; Wong W-K.; Wong, W-Y.; Tetrahedron Lett. 2008, 49 , 1843.

31. Zhu, X-J.; Fu, S-T.; Wong, W-K.; Guo, J-p.; Wong, W-Y.; Angew. Chem., Int. Ed. 2006, 45, 3150.

32. Coskum, A.; Yilmaz, M. D.; Akkaya, E. U.; Org. Lett. 2007, 9, 607.

33. Zhu, M.; Yuan, M.; Liu, X.; Xu, J.; Lv, J.; Huang, C.; Liu, H.; Li, Y.; Wang, S.; Zhu, D.; Org. Lett. 2008, 10, 1481.

34. Tang, Bo.; Huang, H.; Xu, K.; Tong, L.; Yang, G.; Liu, X.; An, L.; Chem. Commun. 2006, 34, 3609.

35. Basheer, M. C.; Alex, S.; Thomas, K. G, Suresh, C. H.; Das, S.; Tetraedron 2006, 62, 605.

36. Fabian, J.; Chem. Rev. 1992, 92, 1197.

37. Lu, Y.; Han, L.; Brinker, C. J.; Niemczyk, T. M.; Lopez, G. P.; Sens. Actuators, B 1996, 35-36, 517.

38. Janotta, M.; Karlowatz, M.; Vogt, F.; Mizaikoff, B.; Anal. Chim. Acta 2003, 496, 339

39. Flavin, K.; Mullowney, J.; Murphy, B.; Owens, E.; Kirwan, P.; Murphy, K.; Hughes, H.; McLoughlin, P.; Analyst 2007, 132, 224.

40. Barone, P. W.; Baik, S.; Heller, D. A.; Strano, M. S.; Nat. Mater. 2005, 4,86 .

41. Barone, P. W.; Parker, R. S.; Strano, M. S.; Anal. Chem. 2005, 77, 7556.

42. Jakusch, M.; Janotta, M.; Mizaikoff, B.; Anal. Chem. 1999, 71, 4786.

43. Gong, S. L.; Yu, Z. J.; Meng, L. Z.; Hu, L.; He, Y. B.; J. Appl. Polym. Sci. 2004, 93, 637.

44. Airoudj, A.; Debarnot, D.; Bêche, B.; Poncin-Epaillard, F.; Talanta 2008, 76, 314.

45. Yang, J.; Liang, S. C.; Anal. Chim. Acta 2005, 537, 385. 
46. Huang, G. G.; Yang, J.; Biosens. Bioelectron. 2005, 21, 408.

47. Lee, C. J.; Yang, J.; Anal. Biochem. 2006, 359, 124.

48. Lin, H. C.; Chou, Y. H.; Yang, J.; Anal. Chim. Acta 2008, 606, 230.

49. Wei, Y. K.; Yang, J.; Talanta 2007, 71, 2007.

50. Lee, C. J.; Yang, J.; Talanta 2008, 74, 1104.

51. Keirsse, J.; Boussard-Plédel, C.; Loréal, O.; Sire, O.; Bureau, B.; Leroyer, P.; Turlin, B.; Lucas, J.; Vib. Spectrosc. 2003, 32, 23.

52. Acha, V.; Meurens, M.; Naveau, H.; Agathos, S. N.; Biotechnol. Bioeng. 2000, 68, 437 .

53. Lucena, R.; Cárdenas, S.; Gallego, M.; Valcárcel, M.; Analyst 2006, 131, 415.

54. Bentrup, U.; Küpper, L.; Budde, U.; Lovis, K.; Jähnisch, K.; Chem. Eng. Technol. 2006, 29, 1216.

55. Roychoudhury, P.; Harvey, L. M.; McNeil, B.; Anal. Chim. Acta 2006 $571,159$.

56. Vojinovic, V.; Cabral, J. M. S.; Fonseca, L. P.; Sens. Actuators, B 2006, $114,1083$.

57. Buerck, J.; Roth, S.; Kraemer, K.; Mathieu, H.; J. Hazard. Mater. 2003 $102,13$.

58. Göbel, R.; Krska, R.; Kellner, R.; Seitz, R. W.; Tomellini, S. A.; Appl. Spectrosc. 1994, 6, 678.

59. Göbel, R.; Seitz, R. W.; Tomellini, S. A.; Krska, R.; Kellner, R.; Vib. Spectrosc. 1995, 8, 141.

60. Flavin, K.; Hughes, H.; Dobbyn, V.; Kirwan, P.; Murphy, K.; Steiner, H.; Mizaikoff, B.; McLoughlin, P.; Int. J. Environ. Anal. Chem. 2006, $86,401$.

61. Flavin, K.; Hughes, H.; McLoughlin, P.; Int. J. Environ. Anal. Chem. 2007, 87, 29 .

62. Murphy, B.; Kirwan, P.; McLoughlin, P.; Anal. Bional. Chem. 2003, 377, 195.

63. Murphy, B.; Kirwan, P.; McLoughlin, P.; Vib. Spectrosc. 2003, 33, 75.

64. Regan, F.; Walsh, F.; Walsh, J.; Int. J. Environ. Anal. Chem. 2003, 83, 621.

65. Regan, F.; MacCraith, B. D.; Walsh, J. E.; O`Dwyer, K.; Vos, J. G.; Meaney, M.; Vib. Spectrosc. 1997, 14, 239.

66. Walsh, J. E.; MacCraith, B. D.; Meaney, M.; Vos, J. G.; Regan, F.; Lancia, A.; Artjushenko, S.; Analyst 1996, 121, 789.
67. McCue, R. P.; Walsh, J. E.; Walsh, F.; Regan, F.; Sens. Actuators, B 2006, 114, 438.

68. Kraft, M.; Jakusch, M.; Karlowatz, M.; Katzir, A.; Mizaikoff, B.; Appl. Spectrosc. 2003, 6, 591 .

69. Janotta, M.; Katzir, A.; Mizaikoff, B.; Appl. Spectrosc. 2003, 7, 823.

70. Heglund, D. L.; Tilotta, D. C.; Environ. Sci. Technol. 1996, 30, 1212.

71. Merchman, S. A.; Lubbad, S. H.; Tilotta, D. C.; J. Chromatogr., A 1998, $829,377$.

72. Silva, A. M. S.; Pimentel, M. F.; Raimundo Jr., I. M.; Almeida, Y. M. B.; Vib. Spectrosc. 2008, 46, 39.

73. Degrandpre, M. D.; Burgess, L. W.; Appl. Spectrosc. 1990, 44, 273.

74. Tobiska, P.; Chomát, M.; Matejec, V.; Berková, D.; Hüttel, I.; Sens. Actuators, B 1998, 51, 152.

75. Bürck, J.; Conzen, J. P.; Ache, H. J.; Fresenius'J. Anal. Chem. 1992, 342, 394.

76. Conzen, J. P.; Bürck, J.; Ache, H. J.; Appl. Spectrosc. 1993, 47, 753.

77. Conzen, J. P.; Bürck, J.; Ache, H. J.; Fresenius' J. Anal. Chem. 1994, 348,501 .

78. Bürck, J.; Conzen, J. P.; Beckhaus, B.; Ache, H. J.; Sens. Actuators, B 1994, 18-19, 291.

79. Buerck, J.; Roth, S.; Kraemer, K.; Scholz, M.; Klaas, N.; J. Hazard. Mater. 2001, 83, 11.

80. Mayer, J.; Bürck, J.; Ache, H. J.; Fresenius`J. Anal. Chem. 1996, 354, 841.

81. Zimmermann, B.; Bürck, J.; Ache, H. J.; Sens. Actuators, B 1997, 41, 45.

82. Chomat, M.; Berkova, D.; Matejec, V.; Kasik, I.; Kuncova, G.; Hayer, M.; Sens. Actuators, B 2002, 87, 258.

83. Skokankova, J.; Mrazek, J.; Matejec, V.; Hayer, M.; Kasik, I.; Chomat, M.; Berkova, D.; Barau, A.; Zaharescu, M.; Raileanu, M.; Mater. Sci. Eng., C 2006, 26, 208.

84. Blair, D. S.; Anal. Chem. 1997, 69, 2238

85. Santoyo, A. T.; Shlyagin, M. G.; Jimenez, F. J. M.; Oyarzabal, L. N. R.; Opt. Commun. 2007, 271, 386.

86. Albuquerque, J. S.; Pimentel, M. F.; Silva, V. L.; Raimundo Jr., I. M.; Rohwedder, J. J. R.; Pasquini, C.; Anal. Chem. 2005, 77, 72.

87. Lima, K. M. G.; Raimundo Jr., I. M.; Pimentel, M. F.; Sens. Actuators, B 2007, 125, 229 . 